\title{
Pro-environmental Behavior of University Students: Influence of Cultural Differences
}

\author{
Ecem Tezel $^{1}$, Dr. Mehmet Ugural ${ }^{2}$, Dr. Heyecan Giritli ${ }^{3}$
}

\begin{abstract}
Responsible Consumption and Production, among the Sustainable Development Goals, indicates that humans should be aware of environmental problems which are to some extent, direct or indirect consequences of their behaviors. This indicates that the question of what shapes proenvironmental behavior (PEB) is difficult to understand. There has been an increasing concern towards individuals' PEBs both at home and in the workplace. However, although some studies have shown significant concern-behavior relationship, others have revealed that environmental concern (EC) fails to predict PEB. Thus, whether individuals with higher levels of environmental concern perform more $\mathrm{PEB}$ has not received robust empirical support. Drawing on the corresponding literature, concern-behavior gap can be explained by the concept of cultural environmental biases. This study aims to test how cultural biases shape PEB. Following the model proposal which explores the effect of cultural biases on EC and PEB, a 42-item questionnaire has been developed and applied with the university students as they are expected to be the most informed and aware people about environmental issues. The findings are expected to deepen the understanding of concern-behavior relationship and cultural environmental biases as well as provide new insights for sustainable development practices.
\end{abstract}

Keywords: pro-environmental behavior, environmental concern, cultural environmental biases, sustainable development goals

\section{Introduction}

The underlying logic of sustainable development is to provide sustainable and resilient future for humans and planet. In addition to drastic influence of policies or regulations developed by global authorities, the unignorable contribution of individual level efforts on natural environment has been emphasized by various researchers many times (Turaga et al., 2010; Zenelaj, 2013). In this context, pro-environmental behavior (PEB) of humans can be considered as an important individual level effort since human activities are discussed and proved as one of the major reasons of environmental problems (Stern, 2000; Chen et al., 2017).

UN General Assembly adopts "Goal-12: Responsible Consumption and Production" as one of the goals for 2030 Agenda for Sustainable Development. Goal-12 targets to increase the awareness about sustainable development by providing accurate information to all people around the world and promoting lifestyles compatible with nature (UN, 2015). In fact, ensuring the highest awareness level about environmental issues for the highest PEB of all people is not an easy task due to the various influencing factors identified by a myriad of researchers. According to the findings of recent PEB studies,

\footnotetext{
$\mid{ }^{1}$ Research assistant at Faculty of Architecture of Istanbul Technical University, Turkey.
}

${ }^{2}$ Assistant Professor at Faculty of Civil Engineering of Istanbul Kultur University, Turkey. 
individuals' concerns about environment and their cultural orientations towards nature may reveal new insights for promotion of PEB (Kollmuss \& Agyeman, 2002; Bamberg \& Möser, 2007; Adger et al., 2013; Price et al., 2014; Tam \& Chan, 2017).

From this point forth, this study aims to investigate the relationship between environmental cultural biases, environmental concern (EC) and PEB. In order to ensure the study is conducted with participants who have certain knowledge about environmental problems and sustainable development concept, authors intended to select the sample from university students.

\section{Pro-environmental Behavior}

It is possible to find close definitions of PEB in literature. For Kollmuss and Agyeman (2002), PEB can be defined as "behavior that consciously seeks to minimize the negative impact of one's actions on the nature and built world". Similarly, Lynn (2014) emphasizes the adverse effect of behavior on nature while defining PEB as "the behavior that has less of negative impact than an alternative behavior". On the other hand, Steg and Vlek (2009) address desired results of behavior as well as undesired results and define PEB as "behavior that harms the environment as little as possible, or even benefits the environment". Apart from the PEB definitions given above, a brief literature review reveals various approaches about environmentally oriented human behavior. For instance; "environmental actions" by Axelrod and Lehman (1993), “ecological behavior” by Kaiser (1998), “environmentally responsible behavior” by De Young (2000), "environmentally significant behavior" by Stern (2000) or recently "sustainable behavior" by Tapia-Fonllem et al. (2013) are some of the highly refereed concepts similar to PEB.

\subsection{Influential Factors and Measurement of PEB}

As stated earlier, human actions have important influence on nature in either way. Thus, understanding and motivating people's behavior into environmental protection manner can be assumed as a judicious approach (Fransson \& Garling, 1999; Manning, 2009; Klöckner, 2013; Steg et al., 2014). To contribute natural environment, firstly, underlying reasons behind pro-environmental behavior should be wellunderstood. Despite PEB researchs showed successive development through focusing on previous studies, each study has its own logic when defining and associating influential factors on PEB. In this context, Kollmuss and Agyeman (2002) examined existing literature and compiled those factors into three main categories as; demographic, external (institutional, economic and social and cultural) and internal (motivation, environmental knowledge, value, attitude, environmental awareness, emotional involvement, locus of control and responsibility and priorities) factors. Similarly, Steg and Vlek (2009) categorized those factors as; motivational (weighing costs and benefits, moral and normative concerns and affect), contextual and habitual factors. Later on, McDonald (2014) grouped the introduced factors in previous studies into five headings; intrapersonal, interpersonal, motivational, psychosocial and environmental education factors. Finally, Kurisu (2015) summarized the influential factors as; barriers and accelerators, psychological factors (norm, attitude, affect and cognitive dissonance), cost 
and benefit (monetary cost and time and effort), knowledge, sociodemographics (gender, age and education and income), personality and situational factors.

In early times of research, simple and linear models were developed to explain the reasons of PEB and awareness about environmental issues was accepted as the strongest determinant. However, limited effect of increasing environmental awareness of individuals through education on PEB were pointed out in a short span of time (Kollmuss and Agyeman, 2002). Later PEB models are relatively more complex as they include more variables and can be categorized into two parts: general behavior models applicable for PEB and PEB specific models (Kurisu, 2015).

In the first category, Schwartz's Norm-Activation Model (1977), Fishbein and Ajzen's Theory of Reasoned Action (1975) and Ajzen's Theory of Planned Behavior (1991) are the well-known behavior models that can be utilized for explaining the reasons of PEB. To begin with, in Norm-Activation Model (NAM), Schwartz investigated the generation of altruistic behaviors, and as pro-environmental behavior is "a mixture of self-interest and of concern for other people, the next generation, other species or whole ecosystems" (Bamberg \& Möser, 2007), NAM can be considered as an applicable model while exploring the antecedents of PEB. Schwartz (1977) claimed that, an individual's awareness about the results of acting in a specific way (awareness of consequences-AC) leverages the target behavior, while that individual's denial of acting in that specific way (responsibility of denial-RD) unbraces it. In order to show behavior, personal norms of an individual need to be stimulated by these two concepts. In Theory of Reasoned Action (TRA), Fishbein and Ajzen (1975) argued the behavioral intention, which has been influenced by individual's willingness to specific behavior (attitude toward behavior) and that individual's belief about whether society think he/she should do that behavior (subjective norm), as a strong antecedent of behavior. According to Fishbein and Ajzen (1975), attitude and subjective norms cannot directly influence the behavior itself but behavioral intention. Finally, in Theory of Planned Behavior (TPB), Ajzen (1991) added the perceived behavioral control, that refers to an individual's belief in his/her own ability or capacity to do certain behavior, as an exogenous variable to the TRA model and claimed the direct and indirect effects of perceived behavioral control on targeted behavior.

In the second category, Value-Belief-Norm Theory of Stern (2000) is highly accepted and studied model for exploring PEB in various domains. In Value-Belief-Norm (VBN) Theory, personal values, ecological worldview, adverse consequences for valued objects, perceived ability to reduce threat and sense of obligation to take pro-environmental actions are considered as successive variables needed for generation of PEB. Stern (2000) explained VBN theory as a combination of value theory, norm-activation theory and NEP and discussed VBN theory as a better predictor of PEB compared to other theories developed thus far. Apart from Stern's theory, there exist various meta-analytical models to explain determinants of PEB. Hines et al. (1987) conducted a meta-analysis with more than a hundred studies and developed a model which investigates the determinants of PEB according to the relationships among cognitive, psychosocial and demographic factors. In their model, Hines et al. (1987) indicated behavioral intention and situational factors as determinants of PEB. According to Bamberg and Möser (2007), researchers explained behavioral intention as a "summarizing" variable of the 
interaction between cognitive and personality variables. After two decades, Bamberg and Möser (2007) advanced Hines et al.'s approach and proposed a meta-analytical structured equation model (MASEM) for PEB. Bamberg and Möser (2007) indicated behavioral intention as the determinant of PEB and perceived behavioral control, attitude and moral norm as explaining variables of intention. According to the model, social norm has indirect influence while moral (personal) norm has direct influence on intention (Bamberg \& Möser, 2007). Few years later, Klöckner (2013) argued the need of one integrative model to predict $\mathrm{PEB}$ and developed the Comprehensive Action Determination Model (CADM) based on prospering behavior models previously developed. Differing from previous studies, perceived behavioral control and habits, as well as intention, were determined as the direct predictors of PEB (Klöckner, 2013).

\subsection{Effects of Environmental Concern and Cultural Biases on PEB}

Environmental concern (EC) represents "the affect associated with environmental problems" (Schultz et al., 2005). Fransson and Garling (1999) summarized EC as "an evaluation of or an attitude towards facts, one's own behavior or others' behavior with consequences for the environment”. In early models, EC was quoted as a powerful determinant of PEB and/or PEB intention (Harland et al., 1999; Fujii, 2006; Lee et al., 2014) and individuals with higher concern about environment were expected to act more pro-environmentally, compared with less concerned ones (Tam \& Chan, 2017). However, more knowledge and concern about environmental problems failed to predict PEB in forthcoming studies (Kollmuss \& Agyeman, 2002) and this inefficacy has been widely studied for decades. Despite some studies did not support any effect of culture on environmentally oriented actions, some argued cultural differences (Kollmuss \& Agyeman, 2002; Fujii, 2006; Bamberg \& Möser, 2007; Adger et al., 2013) as a reason of the "concern-behavior gap" as defined by Tam and Chan (2017).

Cultural environmental biases approach modifies the Cultural Theory of Douglas and Wildavsky (1982) in order to explain the influence of belief systems on individuals' worldviews about nature and environment (Lima \& Castro, 2005; Price et al., 2014). In their study, Price et al. (2014) emphasized the strong and direct connection among EC, cultural biases and specific environmental behaviors. More recently, Tam and Chan (2017) revealed the weak influence of EC on PEB due to cultural differences and emphasized the need for culturally oriented communication strategies to accomplish meaningful progress in PEB.

\section{Research Method}

Purpose of this study is to investigate the influence of culture on environmental concern and PEB. In order to understand how cultural differences may affect EC and PEB of university students from various countries, authors proposed a model that examines cultural differences as an influential variable on EC and PEB. Paired samples $t$ test and one-way ANOVA analyses were conducted with SPSS software to compare and enlighten the differences among students in terms of study variables. 


\subsection{Participants and Procedure}

Data were collected by means of a 42-item questionnaire. Sample consisted of 110 university students from Istanbul Technical University and Istanbul Kultur University, including both undergraduate and graduate students. The demographic characteristics of the respondents are shown in Table 1 to reflect a better profile of the sample. The sample was purposely selected from university students as they were expected not only to be most informed individuals about today's environmental problems but also to be future actors of sustainable development (Conte, 2016).

Table 1. Characteristics of study sample

\begin{tabular}{llcc}
\hline $\begin{array}{l}\text { Demographic } \\
\text { variables }\end{array}$ & Categories & $\begin{array}{c}\text { Number of } \\
\text { responses }\end{array}$ & $\begin{array}{c}\text { Percentage of } \\
\text { responses (\%) }\end{array}$ \\
\hline Gender & Female & 35 & 31.8 \\
& Male & 73 & 66.4 \\
& Prefer not to say & 2 & 1.8 \\
\hline Education & Undergraduate & 62 & 56.4 \\
& Graduate & 48 & 43.6 \\
\hline Nationality & Turkey & 74 & 67.3 \\
& Middle East & 21 & 19.1 \\
& Europe & 15 & 13.6 \\
\hline
\end{tabular}

As is seen from Table 1, male students (66.4\%) outnumbered female students (31.8\%). About $56.5 \%$ of respondents are undergraduate students while $43.6 \%$ are working towards graduate degrees. Among the students, $67.3 \%(n=74)$ were Turkish, 19.1\% $(n=21)$ were Middle Eastern and 13.6\% $(n=15)$ were European.

\subsection{Instrument}

Environmental concern of the respondents were measured with the New Ecological Paradigm (NEP) scale. NEP (Dunlap et al., 2000), the revised version of New Environmental Paradigm (Dunlap \& Van Liere, 1978), is measuring nature oriented (ecocentric) and human oriented (anthropocentric) worldviews by means of (a) limits of growth, (b) anti-anthropocentrism, (c) fragility of nature's balance, (d) rejection of human exemptionalism and (e) belief in eco-crisis dimensions. Asilsoy et al. (2016) stated NEP as a widely used scale in assessing the environmental concern of individuals. In this study, respondents were asked to indicate the extent to which they disagree or agree to each NEP statements from 1 (strongly disagree) to 5 (strongly agree).

Cultural environmental biases of respondents were determined according to four dimensions (egalitarianism, individualism, hierarchism and fatalism) explained in Price et al. (2014)'s study and respondents were asked to indicate the extent to which they disagree or agree to each statement from 1 (strongly disagree) to 5 (strongly agree). Among these dimensions, egalitarian individual believes the fragility of nature and tends to act more pro-environmentally. Conversely, an individualist sees the nature as a resilient phenomenon and does not worry about negative outcomes of human actions for nature. A hierarchical individual supports policies or regulations for the controllable use of natural resources and acquiesce more consumption of people in higher sociohierarchical levels. Finally, a fatalist individual believes the unpredictable presence of 
nature and does not trust his/her power to solve environmental problems.

After environmental concern and cultural bias measures, respondents were asked to specify how frequently they practice of given 10 pro-environmental behaviors in their daily routines (from 1-never to 5-always). The investigated behaviors were determined according to an in-depth literature survey of previous studies as well as PEB lists of various institutions.

The reliability analysis of the questionnaire was carried out by Cronbach's alpha method. Despite the Cronbach's alpha coefficients of subscales are ranged from 0.41 to 0.73 , the internal consistency value of the complete questionnaire reveals 0.65 which indicates acceptability as well as questionability of survey results.

\section{Results}

In order to understand the influence of cultural differences on environmental concern and PEB, first, environmental cultural tendencies of students were determined through paired samples t-test analysis using SPSS 21.0 software. According to the results displayed in Table 2, students are significantly show egalitarian tendency about environment as their values are ranging from $4.744(\mathrm{p}<.000)$ to $13.671(\mathrm{p}<.000)$. Furthermore, second environmental cultural tendency of students is hieararchical, as their values are 8.673 and $10.211(\mathrm{p}<.000)$. However, there is no significant difference between individualist and fatalist cultural tendencies about environment.

Table 2. Paired samples t-test

\begin{tabular}{lccccc}
\hline Measures & Mean & SD & t & df & Sig. \\
\hline Hierarchical-Egalitarian & -.307 & .679 & -4.744 & 109 & .000 \\
Hierarchical-Individualistic & .907 & 1.097 & 8.673 & 109 & .000 \\
Hierarchical-Fatalist & 1.067 & 1.096 & 10.211 & 109 & .000 \\
Egalitarian-Individualistic & 1.214 & 1.014 & 12.557 & 109 & .000 \\
Egalitarian-Fatalist & 1.374 & 1.054 & 13.671 & 109 & .000 \\
Individualist-Fatalist & .160 & 1.02 & 1.636 & 109 & .105 \\
\hline
\end{tabular}

Second, students in the study sample was divided into three categories according to their countries of origin. Using SPSS 21.0 software, one-way ANOVA test was conducted to investigate the differences among Turkish, Middle Eastern and European students (see Table 3). Since the sample did not have a balanced population distribution of nations (Turkish=74, Middle Eastern=21 and European=15), group comparisons were conducted through Hochberg's GT2 post hoc test.

Table 3. One-way ANOVA results

\begin{tabular}{lccccc}
\hline Measures & $\mathbf{N}$ & Mean & SD & F & Sig. \\
\hline Ecocentric & 110 & 3.909 & .571 & 14.266 & .000 \\
Anthropocentric & 110 & 2.836 & .576 & 4.189 & .018 \\
Hierarchical & 110 & 3.960 & .729 & 4.912 & .009 \\
Egalitarian & 110 & 4.267 & .638 & 6.978 & .001 \\
Individualist & 110 & 3.053 & .746 & 3.084 & .050 \\
Fatalist & 110 & 2.893 & .780 & .502 & .607 \\
PEB & 110 & 3.608 & .580 & 5.679 & .005 \\
\hline
\end{tabular}


One-way ANOVA results indicate significant differences in worldview means of students according to their countries of origin. For example, considering the ecocentric worldview, there are meaningful differences between Turkish and Middle Eastern students $(p=.000)$ and European and Middle Eastern students $(p=.017)$. Students from Middle East countries have significantly lower ecocentric concern about nature compared with the students from Turkey and European countries. On the other hand, the significant difference of anthropocentric worldview between European and Middle Eastern students $(p=.014)$ reveals more anthropocentric concern of European students. According to the post hoc results, Turkish and Middle Eastern students show significant differences in terms of hierarchical $(p=.007)$ and egalitarian $(p=.001)$ cultural tendencies. Such result displays more hierarchical and egalitarian cultural tendencies of Turkish students compared with Middle Eastern students. However, there exists no significant differences in any cultural biases between Turkish and European and between Middle Eastern and European students.

Finally, statistical analysis on PEB of students unfold significant contrasts. According to post hoc results, both Turkish and European students show more pro-environmental behaviors compared with Middle Eastern students $(\mathrm{p}=.009$ and $\mathrm{p}=.012)$, while Turkish and European students do not show any meaningful difference in terms of PEB.

\section{Discussion and Conclusion}

Overall, findings of this study provided some insights about the relationship among environmental cultural biases, EC and PEB. Paired samples t-test results reveal the significant egalitarian and hierarchical tendencies of the study participants about environment. Also, ANOVA results indicate that, Turkish students have higher hierarchical and egalitarian cultural tendencies compared with remaining sample. The higher tendency for hierarchical bias makes students to support regulations about attentive use of natural resources. Additionally, since higher egalitarian tendency signifies higher environmentally concerned behaviors, Turkish students are expected to act more pro-environmentally. Despite there exist no significant difference between Turkish and European students in terms of PEB, the differences between Turkish and Middle Eastern and European and Middle Eastern students are partially coincide with the existing studies. Such that, Morren and Grinstein (2016) noted the connection between PEB and economic development level of nations and stated more environmentally oriented behaviors of developed countries. Besides, Vicente-Molina et al. (2013) emphasized possible influence of varying cultural habits on PEBs of students.

On the other hand, this study has certain limitations as well. First, despite the number of respondents in the study is relatively high, equal distribution of respondents' nations could not been achieved. However, authors conducted Hochberg's GT2 post hoc test to prohibit unbalanced group comparisons. Second, moderate internal consistency score of the questionnaire discredits the results of this study. Despite, environmental concern and PEB scales displayed relatively high reliability scores, the poor reliability of environmental cultural tendency scale might be resulted from rough statements of survey items, such as; "Often there is no explanation or reason for the things happen in the natural environment" or "the natural environment is capable of recovering from any 
damage humans may cause". Last, despite many researchers indicated that different behaviors have been affected by different factors (Stern, 2000; Gatersleben et al., 2002; Kollmuss \& Agyeman, 2002; Lynn, 2014) and recommended investigation of each behavior separately, pro-environmental behavior was considered as a single concept in this study because authors aimed to understand the general environmentally responsible behavior tendency of respondents.

Despite the mentioned limitations, this study reveals significant differences between PEB of students due to their cultural tendencies. However, environmental issues are not country specific problems, thus cannot be solved by country specific solutions. In order to achieve a successful sustainable development globally, culture should seen as an important accelerator rather than a barrier. In fact, Adger et al. (2012) noted lack of integration of cultural dimension into environmental analysis and policies and emphasized culture as an important factor for the success of strategies developed against environmental problems. On the other hand, Vicente-Molina et al. (2013) indicated university students as the future of societies and emphasized the importance of their environmentally oriented education on nations' progress toward sustainability. Similarly, Zenelaj (2013) and Conte (2016) stated the role of education for global sustainable development.

Taking into account all of these, PEB can said to be an important individual level action against environmental problems. The influence of culture on PEB will also influence nations' sustainable development level accordingly. Education, on the other hand, is an inseparable part of sustainable development concept. Thus, authorities should develop specific education strategies for sustainable development which turns cultural differences into advantage.

\section{References}

Adger, N., Barnett, J., Brown, K., Marshall, N., \& O’Brien, K. (2013). Cultural dimensions of climate change impacts and adaptation. Nature Climate Change, 3(2), 112-117.

Ajzen, I. (1991). The theory of planned behavior. Organizational Behavior and Human Decision Processes, 50(2), 179-211.

Asilsoy, B., Laleci, S., Yıldırım, S., Uzunoğlu, K., \& Fuller, Ö. Ö. (2016). Evaluation of Environmental Worldview from the perspectives of undergraduate students in N. Cyprus. European Journal of Sustainable Development, 5(4), 233-241.

Axelrod, L. J., \& Lehman, D. R. (1993). Responding to environmental concerns: What factors guide individual action. Journal of Environmental Psychology, 13(2), 149-159.

Bamberg, S., \& Möser, G. (2007). Twenty years after Hines, Hungerford, and Tomera: A new meta-analysis of psycho-social determinants of pro-environmental behaviour. Journal of Environmental Psychology, $27(1), 14-25$.

Chen, H., Chen, F., Huang, X., Long, R., \& Li, W. (2017). Are individuals' environmental behavior always consistent - An analysis based on spatial difference. Resources, Conservation \& Recycling, 125, 25-36.

Clark, F. C., Kotchen, M. J., \& Moore, M. R. (2003). Internal and external influences on pro-environmental behavior: Participation in a green electricity program. Journal of Environmental Psychology, 23, 237-246.

Conte, E. (2016). Sustainability and built environment: The role of higher education in architecture and building engineering. European Journal of Sustainable Development, 5(3), 1-10.

DEFRA. (2008). A Framework for Pro-Environmental Behaviors-Annexes. London: Department for Environment Food and Rural Affairs.

De Young, R. (2000). New ways to promote proenvironmental behavior: Expanding and evaluating motives for environmentally responsible behavior. Journal of Social Issues, 56(3), 509-526. 
Douglas, M., \& Wildavsky, A. (1982). Risk. And Culture: An Essay On The Selection Of Technical And Environmental Dangers. Berkeley. California: University of California Press.

Dunlap, R. E., Van Liere, K. D., Mertig, A. G., \& Jones, R. E. (2000). New trends in measuring environmental attitudes: Measuring endorsement of the new ecological paradigm: A revised NEP scale. Journal of Social Issues, 56(3), 425-442.

Dunlap, R. E., \& Van Liere, K. D. (1978). The new environmental paradigm. The Journal of Environmental Education, 9(4), 10-19.

EPA. (2008). Green Building Strategy. Washington, DC: Environmental Protection Agency.

Fishbein, M., \& Ajzen, I. (1975). Belief, Attitude, Intention and Behavior: An Introduction to Theory and Research.

Fransson, N., \& Garling, T. (1999). Environmental concern: Conceptual definitions, measurement methods and research findings. Journal of Environmental Psychology, 19, 369-382.

Fujii, S. (2006). Environmental concern, attitude toward frugality and ease of behavior as determinants of pro-environmental behavior intentions. Journal of Environmental Psychology, 26, 262-268.

Gatersleben, B., Steg, L., \& Vlek, C. (2002). Measurement and determinants of environmentally significant consumer behavior. Environment and Behavior, 34(3), 335-362.

Harland, P., Staats, H., \& Wilke, H. A. M. (1999). Explaining proenvironmental intention and behavior by personal norms and the theory of planned behavior. Journal of Applied Social Psychology, 29(12), 25052528.

Hines, J. M., Hungerford, H. R., \& Tomera, A. N. (1987). Analysis and synthesis of research on responsible environmental behavior: A meta-analysis. The Journal of Environmental Education, 18(2), 1-8.

Kaiser, F. G. (1998). A general measure of ecological behavior. Journal of Applied Social Psychology, 28(5), 395422.

Klöckner, C. A. (2013). A comprehensive model of the psychology of environmental behavior - A metaanalysis. Global Environmental Change, 23, 1028-1038.

Kollmuss, A., \& Agyeman, J. (2002). Mind the gap: Why do people behave environmentally and what are the barriers to pro-environmental behaviour. Environmental Education Research, 8(3), 239-260.

Kurisu, K. (2015). Pro-environmental Behaviors.

Lee, Y.-K., Kim, S., Kim, M.-S., \& Choi, J.-G. (2014). Antecedents and interrelationships of three types of pro-environmental behavior. Journal of Business Research, 67, 2097-2105.

Lima, M. L., \& Castro, P. (2005). Cultural theory meets the community: Worldviews and local issues. Journal of Environmental Psychology, 25, 23-35.

Lynn, P. (2014). Distinguishing dimensions of pro-environmental behaviour. ISER Working Paper Series, 22. Retrieved from https://www.iser.essex.ac.uk/research/publications/working-papers/iser/201419

Manning, C. (2009). The Psychology of Sustainable Behavior. St. Paul, MN: Minnesota State Pollution Control Agency

McDonald, F. V. (2014). Developing an integrated conceptual framework of pro-environmental behavior in the workplace through synthesis of the current literature. Administrative Sciences, 4, 276-303.

Morren, M., \& Grinstein, A. (2016). Explaining environmental behavior across borders: A meta-analysis. Journal of Environmental Psychology, 47, 91-106.

Price, J. C., Walker, I. A., \& Boschetti, F. (2014). Measuring cultural values and beliefs about environment to identify their role in climate change responses. Journal of Environmental Psychology, 37, 8-20.

Schultz, W., Gouveia, V. V., Cameron, L. D., Tankha, G., Schmuck, P., \& Franek, M. (2005). Values and their relationship to environmental concern and conservation behavior. Journal of Cross-cultural Psychology, 36(4), 457-475.

Schwartz, S. H. (1977). Normative influences on altruism. Advances in Experimental Social Psychology, 10(C), 221-279.

Steg, L., Bolderdijk, J. W., Keizer, K., \& Perlaviciute, G. (2014). An integrated framework for encouraging pro-environmental behavior: The role of values, situational factors and goals. Journal of Environmental Psychology, 38, 104-115.

Steg, L., \& Vlek, C. (2009). Encouraging pro-environmental behaviour: An integrative review and research agenda. Journal of Environmental Psychology, 29(3), 309-317.

Stern, P. C. (2000). New environmental theories: Toward a coherent theory of environmentally significant behavior. Journal of Social Issues, 56(3), 407-424. 
Tam, K.-P., \& Chan, H.-W. (2017). Environmental concern has a weaker association with pro-environmental behavior in some societies than others: A cross-cultural psychology perspective. Journal of Environmental Psychology, 53, 213-223.

Tapia-Fonllem, C., Corral-Verdugo, V., Fraijo-Sing, B., \& Durón-Ramos, M. F. (2013). Assessing sustainable behavior and its correlates: A measure of pro-ecological, frugal, altruistic and equitable actions. Sustainability (Switzerland), 5(2), 711-723.

Turaga, R. M. R., Howarth, R. B., \& Borsuk, M. E. (2010). Pro-environmental behavior: Rational choice meets moral motivation. Annals of the New York. Academy of Sciences, 1185, 211-224.

United Nations. (2015). Transforming Our World: The 2030 Agenda for Sustainable Development. Retrieved from http://www.un.org

Vicente-Molina, M. A., Fernandez-Sainz, A., \& Izagirre-Olaizola, J. (2013). Environmental knowledge and other variables affecting pro-environmental behavior: Comparison of university students from emerging and advanced countries. Journal of Cleaner Production, 61, 130-138.

Whitmarsh, L., \& O’Neill, S. (2010). Green identity, green living? The role of pro-environmental self-identity in determining consistency across diverse pro-environmental behaviors. Journal of Environmental Psychology, 30, 305-314.

Zenelaj, E. (2013). Education for sustainable development. European Journal of Sustainable Development, 2(4), 227-232. 